\title{
UMA NOVA ESTRATÉGIA DE OTIMIZAÇÃO APLICADA À SEQUENCIA TERMICAMENTE ACOPLADA DE UM PROCESSO DA DESTILAÇÃO EXTRATIVA
}

\author{
K. D. BRITO, M. F. FIGUEIRÊDO, W. B. RAMOS, L. G. S. VASCONCELOS e R. P. BRITO \\ Universidade Federal de Campina Grande, Departamento de Engenharia Química \\ E-mail para contato: karolineufcg@gmail.com
}

\begin{abstract}
RESUMO - A destilação extrativa é um dos métodos mais usados para separar misturas azeotrópicas. Entretanto, é um processo que consome grande quantidade de energia e o uso de acoplamentos térmicos é uma alternativa para reduzir este consumo. Um procedimento de análise baseado no teor de solvente foi desenvolvido para a sequência termicamente acoplada a um retificador lateral da destilação extrativa. A partir do procedimento proposto, foi possível encontrar o ponto operacional ótimo da sequência estudada e obter resultados qualitativos das principais variáveis de decisão.
\end{abstract}

\section{INTRODUÇÃO}

Os processos de destilação são responsáveis por parcelas representativas do consumo de energia de uma planta química. $\mathrm{O}$ fato desta energia geralmente ser oriunda de fontes não renováveis induz a um iminente racionamento deste insumo. Neste sentido, diversas soluções têm sido anunciadas ao longo dos últimos anos. Entre estas soluções, pesquisas revelam que o uso de acoplamento térmico em sequências convencionais de destilação resulta em significativas reduções no consumo de energia. Estas configurações são obtidas através da interconexão de correntes de processo (uma na fase vapor e a outra na fase líquida) entre duas colunas. Cada interconexão substitui um condensador ou um refervedor de uma das colunas, o que pode resultar em até $30 \%$ de economia no consumo de energia (Kiss e Suszwalak, 2012).

A maior parte das sequências de destilação termicamente acopladas é direcionada para a separação de misturas ternárias envolvendo hidrocarbonetos (Hernández e Jiménez, 1996;). Nos últimos anos, alguns trabalhos propuseram sequências de destilação termicamente acopladas para separar misturas com mais de três componentes (Skogestad et al., 2013) e a aplicação em destilações reativas (Delgado et al., 2012). A aplicação deste conceito na destilação extrativa surgiu somente com o trabalho de Guerra et al. (2008), cuja configuração é conhecida como coluna de destilação extrativa termicamente acoplada a um retificador lateral (TCEDS-SR).

A obtenção do design e ponto ótimo de operação desta sequência se depara com as mesmas dificuldades de uma sequência convencional de destilação extrativa: o sistema de equações que representa o processo é não linear, possui variáveis discretas e contínuas, não possui convexidade e é não-monotônico (Ojeda et al., 2013). Para contornar os obstáculos envolvidos na busca pelo design e 
ponto de operação ótimos, várias metodologias têm sido propostas, podendo incluir o uso de simuladores, métodos gráficos, análise de sensibilidade, técnicas de otimização, planejamento experimental, métodos heurísticos e métodos estocásticos.

Recentemente, um trabalho publicado por Figueirêdo et al. (2014) incluiu um novo parâmetro na análise, o teor de etilenoglicol na região extrativa; mais especificamente, no prato de alimentação do solvente. O uso deste parâmetro permitiu encontrar o intervalo das possíveis soluções que necessariamente irão contemplar o ponto ótimo global de operação, além de eliminar os obstáculos intrínsecos às metodologias de análises do processo da destilação extrativa citados anteriormente.

O objetivo deste trabalho é encontrar o ponto ótimo de operação de uma TCEDS-SR que minimize o consumo de energia, usando o teor de solvente como principal variável de análise. Como estudo de caso, foi considerada separação etanol (ETOH)/água(H2O), cuja dificuldade se deve à existência de um azeótropo de mínimo em concentração molar de 89\% de etanol e 1 atm.

\section{ESTRATÉGIA DE SOLUÇÃO}

Em destilações extrativas, um solvente deve ser adicionado à mistura azeotrópica para alterar o seu equilíbrio líquido-vapor. No caso do sistema etanol/água, o etilenoglicol (EG) enquadra-se dentre os solventes mais adequados para utilização em larga-escala (Meirelles et al., 1992).

Uma forma de observar a influência do solvente sobre o equilíbrio de fases é através de diagrama em base livre de solvente. A Figura 1 mostra que quanto maior a concentração de EG na mistura, mais afastada a curva de equilíbrio está da diagonal. Estas curvas são construídas a partir do cálculo do ponto de bolha usando um vaso flash. Cada curva de equilíbrio representa uma concentração diferente de EG, que é alcançada variando apenas a vazão de solvente que alimenta o flash.

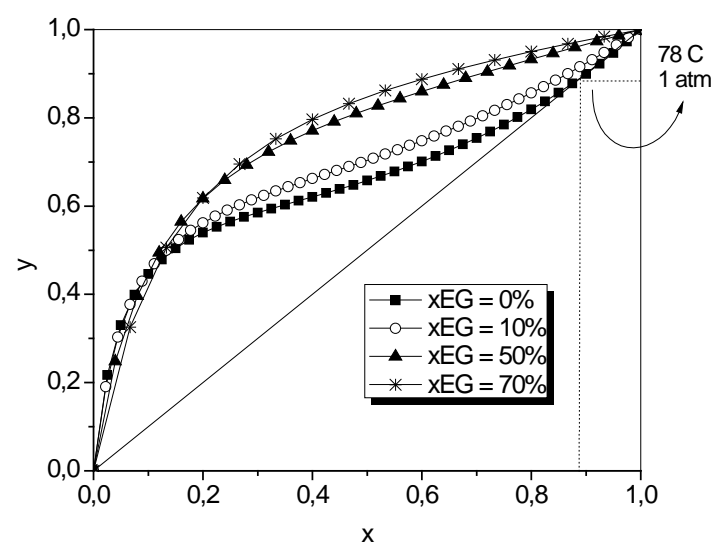

Figura 1 - Diagrama pseudobinário do ELV (NRTL, e pressão igual a 1 atm) para o sistema ETOH/H2O usando diferentes quantidades de EG. 


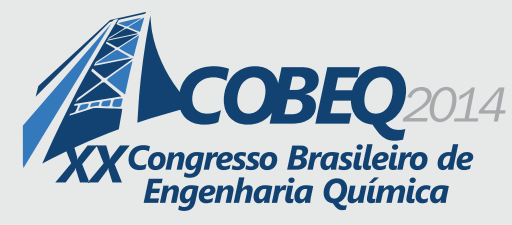

19 a 22 de outubro de 2014
Florianópolis/SC

Ao considerar uma coluna de destilação extrativa, além da vazão de solvente (S), outras variáveis influenciam diretamente a pureza dos produtos e o consumo de energia: razão de refluxo (R), número de estágios da coluna, localização dos estágios de alimentação de solvente e azeótropo binário. Com o objetivo de avaliar apenas condições operacionais, este trabalho considera que o design da TCEDS-SR está fixo.

Se o design está fixo, além da vazão de solvente, a razão de refluxo também deve ser avaliada. Na simulação de uma coluna extrativa e considerando as mesmas restrições de pureza no topo e na base, diferentes condições operacionais de R e S podem ser encontradas, conforme mostra a Figura 2. Neste caso, cada condição operacional resulta em perfis de composição e cargas térmicas diferentes. A partir do perfil de composição de solvente, verificou-se a existência de um platô da composição de EG (na fase líquida) na região extrativa (linha pontilhada), conhecido como teor de solvente, xEG (Figueirêdo et al., 2014). A especificação de xEG no prato de alimentação do solvente garante solução única para a coluna de destilação extrativa. Fazendo analogia com o método de McCabeThiele, é como se existisse uma única reta de retificação que satisfizesse as especificações. Uma análise de sensibilidade neste parâmetro permite encontrar todas as soluções que satisfazem as restrições de pureza, sendo que uma destas soluções corresponde ao ponto operacional ótimo do processo.

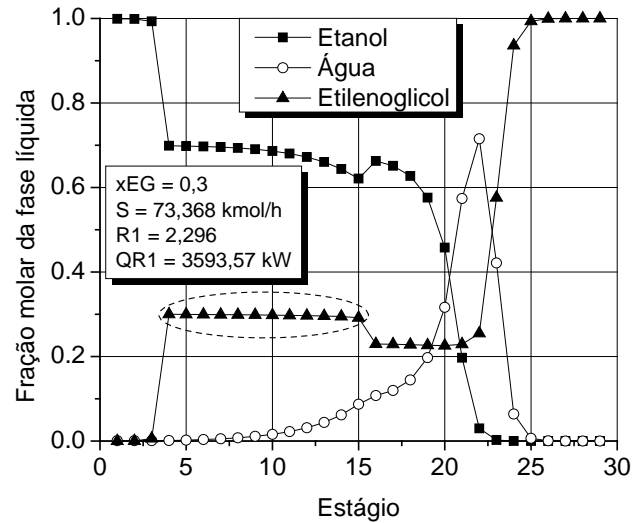

(a)

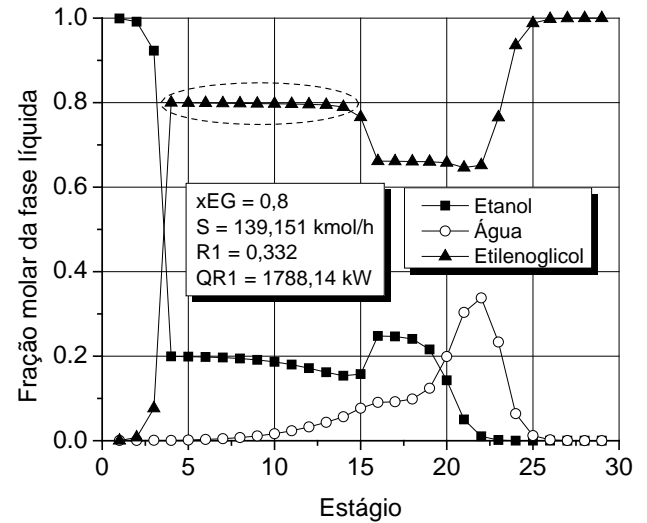

(b)

Figura 2 - Fluxograma do processo de produção. Perfis de composição da fase líquida ao longo de uma coluna extrativa para $\mathrm{xEG}=0,3$ (a) e $\mathrm{xEG}=0,8$ (b).

A Figura 3 mostra o fluxograma contendo as etapas do procedimento utilizado na obtenção do ponto operacional ótimo de uma TCEDS-SR. É importante enfatizar que a vazão de vapor que interconecta a coluna extrativa à coluna lateral também deve ser incluída no procedimento, já que tem impacto direto no consumo de energia. 


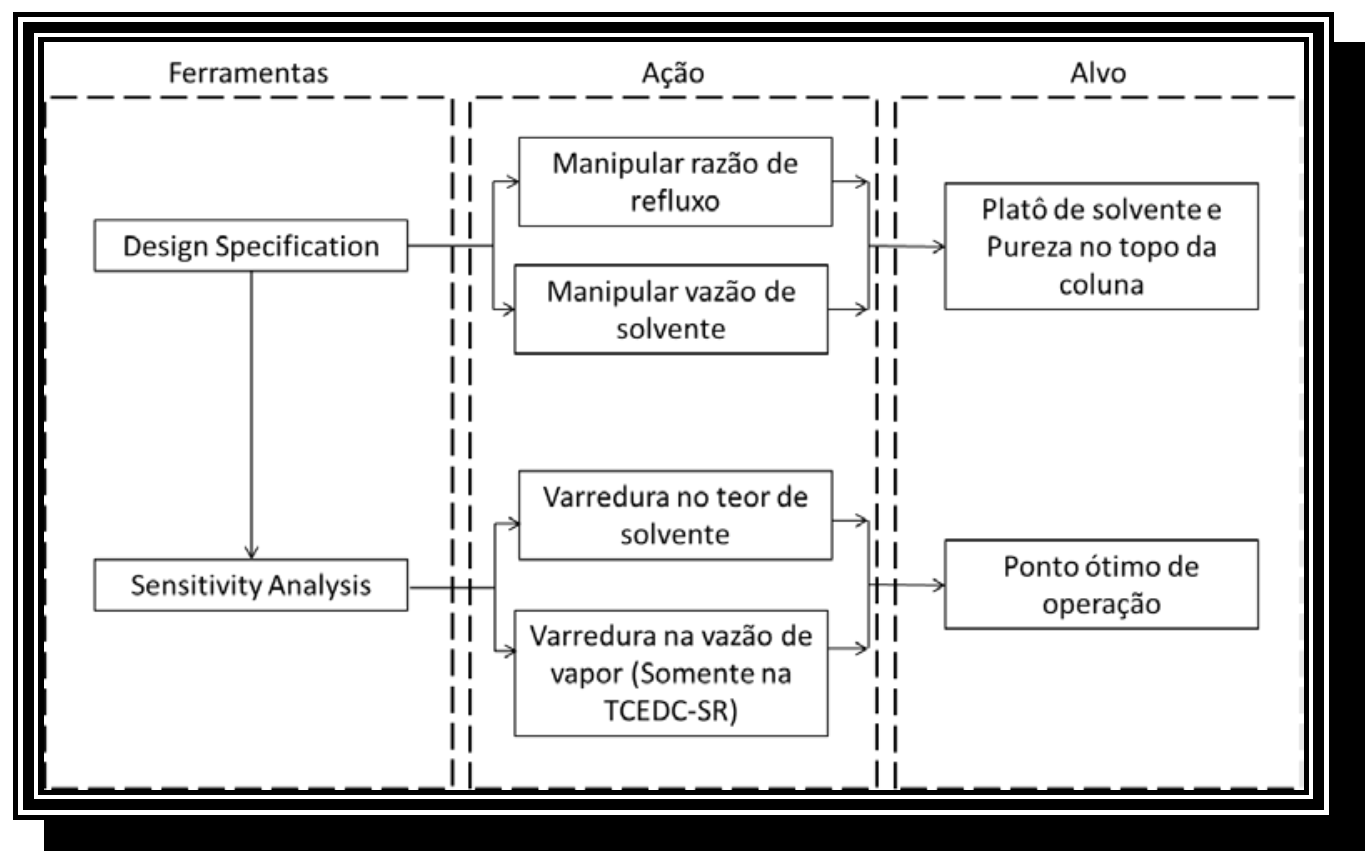

Figura 3 - Procedimento de análise proposto para uma destilação extrativa usando o Aspen Plus®.

\section{SIMULAÇÃO E OTIMIZAÇÃO}

As simulações foram realizadas utilizando o modelo Radfrac ${ }^{\circledR}$ do Aspen Plus ${ }^{\circledR}$. Para representar o equilíbrio líquido vapor foi considerado a abordagem gamma-phi, aonde a fase vapor foi considerada ideal e a não idealidade da fase líquida foi representada pelo modelo termodinâmico NRTL (Meirelles et al., 1992).

A TCEDS-SR usada neste trabalho foi obtida a partir de uma típica sequência convencional da destilação extrativa. O reciclo de solvente foi incluído à TCEDS-SR para reaproveitar o solvente e integrar termicamente com a alimentação de azeótropo; etapas não executadas por Guerra et al. (2008). A TCEDS-SR é mostrada na Figura 4. Os dados para as colunas de destilação (C1 e C2) estão baseados nos trabalhos de Meirelles et al. (1992) e Figueirêdo et al. (2014).

Para a obtenção do caso base, pureza de etanol no topo de C1 e teor de solvente foram as restrições estabelecidas, alcançadas manipulando-se R1 e S. Em C2, apenas uma restrição de topo é especificada. Neste caso, manipula-se a razão de refluxo (R2) para alcançar o limite máximo de EG na corrente H2O. Estas duas etapas são executadas usando o bloco Design Specification do Aspen Plus ${ }^{\circledR}$. Inicialmente a vazão FV que interconecta as colunas C1 e C2 deve ser estimada.

Uma varredura em xEG fornece o conjunto de pontos de operação que satisfazem as restrições de pureza impostas ao processo. Essa varredura é feita através de uma análise de sensibilidade em xEG. Como a vazão que interconecta as duas colunas tem forte efeito sobre o consumo de energia, uma análise de sensibilidade também foi realizada em FV. 


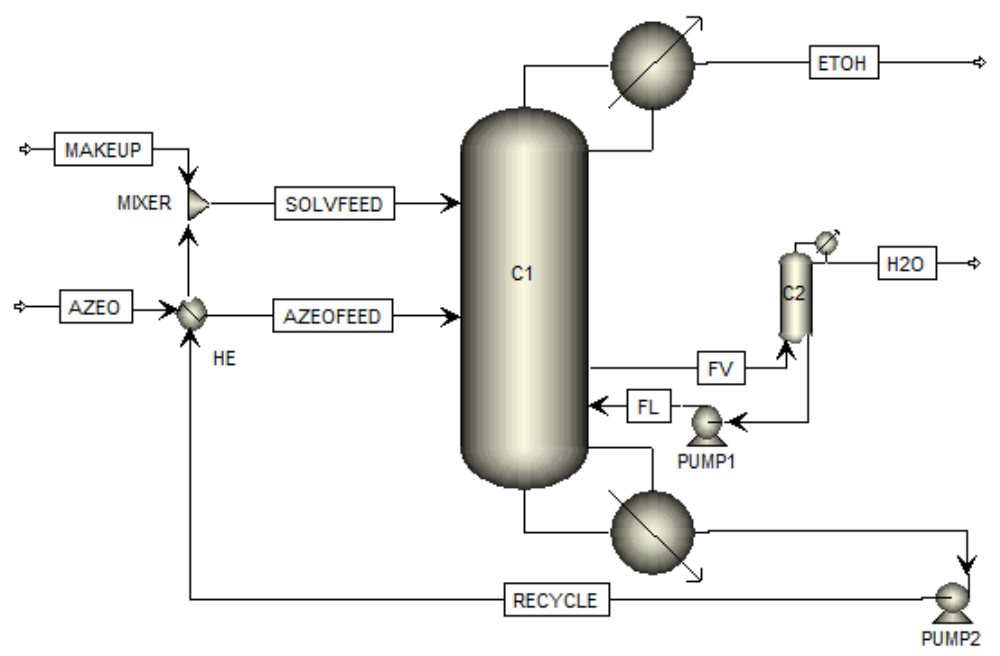

Figura 4 - Fluxograma para o processo de separação ETOH/H2O usando uma TCEDS-SR.

\section{RESULTADOS E DISCUSSÃO}

Para um design fixo, a análise de sensibilidade no teor de solvente determinou o espaço das possíveis soluções de $\mathrm{R} 1$ e $\mathrm{S}$, onde cada par $(\mathrm{R} 1, \mathrm{~S})$ resulta em um valor diferente para a carga térmica de C1 (QR1). A Figura 5 mostra o resultado desta análise para S, R1 e QR1, onde é possível observar que o consumo mínimo de energia da coluna extrativa C1 (Figura 5c) ocorre para a menor razão de refluxo (Figura 5a) e máxima da vazão de solvente (Figura 5b). O procedimento de análise proposto sugere que o teor de solvente é resultado de uma combinação entre S e R1 e isso é confirmado analisando as Figuras 5a e 5b.

Enquanto a Figura 5a mostra que R1 é uma função monotônica decrescente em relação à xEG, a Figura 5b mostra que $\mathrm{S}$ é uma função não-monotônica, e portanto apresenta um ponto de mínimo. $\mathrm{O}$ ponto mínimo de $\mathrm{S}(\mathrm{xEG}=0,4)$ corresponde à vazão mínima que viabiliza a separação. $\mathrm{O}$ fato de $\mathrm{S}$ apresentar um valor mínimo indica que $S$ pode assumir valores iguais; no entanto, R1 não assume valores iguais, já que é função monotônica. Este resultado confirma que o procedimento de análise proposto fornece solução única e em nenhum momento o par (R1, S) será o mesmo.

Em uma TCEDS-SR, todo o fornecimento de energia ocorre por intermédio do único refervedor presente nessa configuração. Portanto, além das variáveis analisadas anteriormente (S e R1), o consumo de energia da TCEDS-SR também é influenciado pela vazão de vapor (FV) que conecta C1 e C2. Através de uma análise de sensibilidade em FV, foi possível encontrar o seu valor ótimo que minimiza QR1 ao mesmo tempo que obedece às restrições de pureza. Dois casos (xEG = 0,3 e xEG = 0,8) são mostrados na Figura 6. Quando o teor de solvente assume valores maiores, o consumo de energia diminui. Para as restrições impostas pelo Design Specification para C1 e C2 da TCEDS-SR, o menor valor alcançado para FV foi de $30 \mathrm{kmol} / \mathrm{h}$, e isso é resultado da menor quantidade de solvente vaporizada pelo refervedor da coluna C1. 


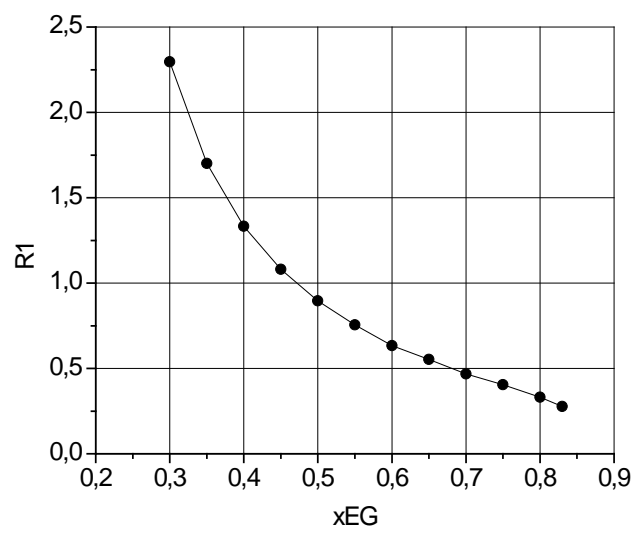

(a)

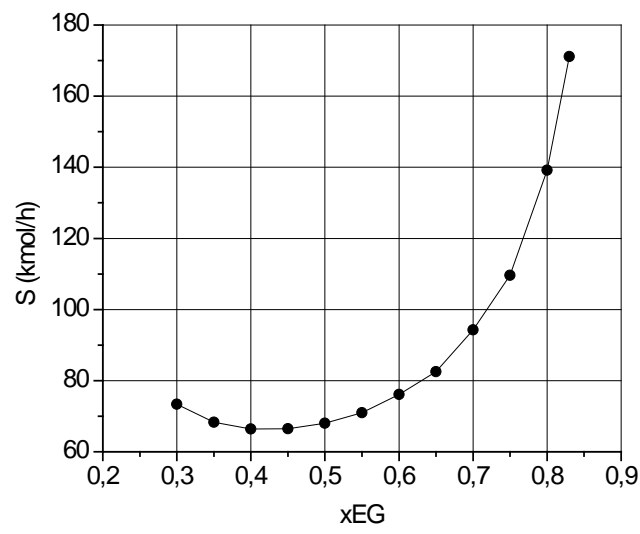

(b)

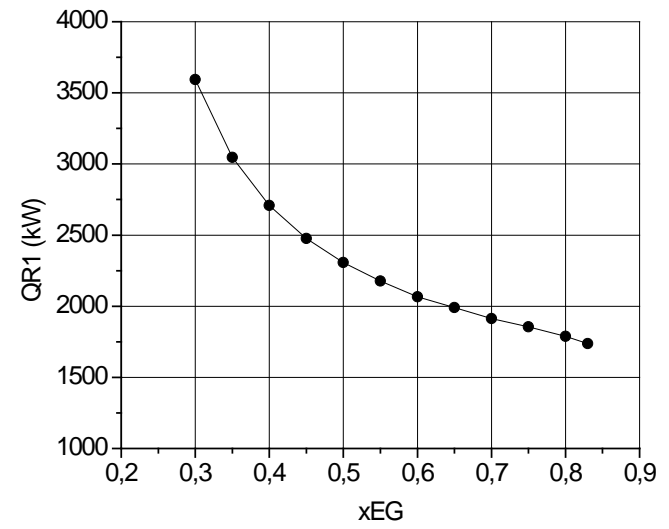

(c)

Figura 5 - Razão de refluxo de C1 (a), vazão de solvente (b) e carga térmica de C1 (c) versus teor de EG.

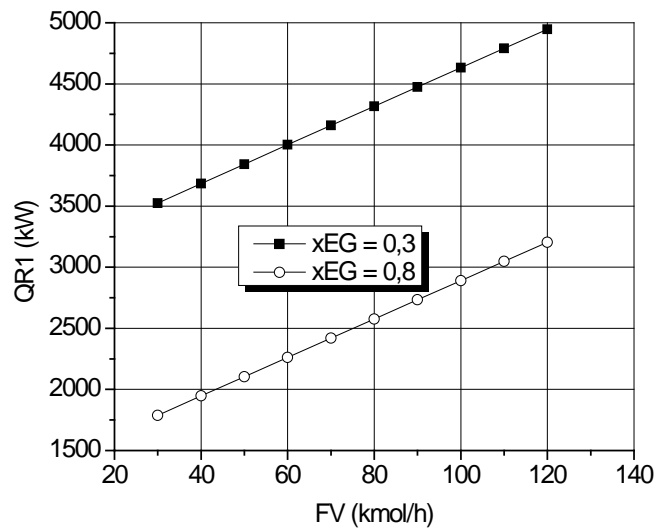

Figura 6 - Carga térmica do refervedor QR1 versus vazão FV para xEG = 0,3 e xEG = 0,8. 
É importante mencionar que a razão S/F (vazão de solvente/alimentação de azeótropo) não foi considerada nesse trabalho, pois do ponto de vista qualitativo, o comportamento de $\mathrm{S}$ e $\mathrm{S} / \mathrm{F}$ são iguais. De fato, a razão S/F é avaliada para fins de controle. Em geral, o maior distúrbio de uma planta é a alimentação da mistura azeotrópica (F); como a vazão de solvente $\mathrm{S}$ depende da alimentação $\mathrm{F}$, é preferível utilizar um controle de razão para manter S/F em um set point, ao invés de tentar ajustar S e F simultaneamente. O controle de razão trabalha com uma variável de distúrbio (F) e uma variável manipulada (S).

O cenário ótimo do ponto de vista de consumo de energia é mostrado na Tabela 1.

\begin{tabular}{|}
$\mid$\begin{tabular}{|c|c|}
\hline \multicolumn{2}{|c|}{ Tabela 1 - Cenário ótimo da TCEDS-SR } \\
\hline Teor de solvente & 0,83 \\
\hline Razão de refluxo de C1 & 0,28 \\
\hline Vazão de solvente (kmol/h) & 171,12 \\
\hline Consumo mínimo de energia (kW) & 1737,33 \\
\hline
\end{tabular}
\end{tabular}

A Tabela 2 faz uma comparação entre os resultados obtidos neste trabalho e outros encontradas na literatura. No ponto ótimo da TCEDS-SR, ela é a configuração mais atrativa do ponto de vista de consumo específico de energia. De fato, a comparação com dados da literatura foi realizada com objetivo de verificar a consistência dos resultados obtidos, visto que, vários fatores influenciam no consumo específico de energia; por exemplo, a eficiência das colunas e os dados de ELV.

Tabela 2 - Consumo específico de energia para diversas tecnologias na obtenção de etanol anidro.

\begin{tabular}{|c|c|c|}
\hline Tipo de processo & $\begin{array}{c}\text { Concentração de etanol } \\
\text { (molar \%) }\end{array}$ & MJ/kg de etanol \\
\hline $\begin{array}{c}\text { Kiss et al. (2012): Sequência convencional da } \\
\text { destilação extrativa com EG }\end{array}$ & 0,999 & 1,836 \\
\hline $\begin{array}{c}\text { Li e Bai (2012): Sequência convencional da } \\
\text { destilação extrativa com três colunas usando EG }\end{array}$ & 0,9995 & 2,24 \\
\hline $\begin{array}{r}\text { Meirelles et al. (1992): Sequência convencional da } \\
\text { destilação extrativa com EG }\end{array}$ & 0,995 & 1,94 \\
\hline Este trabalho: TCEDS-SR com EG & 0,999 & 1,597 \\
\hline
\end{tabular}

\section{CONCLUSÕES}

O procedimento proposto neste trabalho foi aplicado com sucesso para uma TCEDS-SR. A especificação do teor de solvente no prato de alimentação deste componente na coluna extrativa representa uma nova fase para o entendimento e busca por condições operacionais ótimas deste 
processo, pois elimina um dos principais problemas de destilações extrativas: a multiplicidade de soluções. Ao avaliar o teor de solvente, duas variáveis fundamentais no processo de destilação extrativa estão sendo consideradas simultaneamente: razão de refluxo da coluna extrativa e vazão de solvente. O resultado para o mínimo consumo de energia ocorre para a menor razão de refluxo e maior vazão de solvente. Comparando o consumo específico de energia da TCEDS-SR com configurações encontradas na literatura, a TCEDS-SR é a mais atrativa.

\section{REFERÊNCIAS}

DELGADO, R. D.; HERNÁNDEZ, S.; MUÑOZ, F. O.; HERNÁNDEZ, J. G.; MONTOYA, J. C. From Simulation Studies to Experimental Tests in a Reactive Dividing Wall Distillation Column. Chem. Eng. Res. Des., v. 90, p. 855-862, 2012.

FIGUEIRÊDO, M. F.; BRITO; K. D.; BRANDÃO, W.; BRITO, R. P. Effect of Solvent Content on the Separation and the Energy Consumption of Extractive Distillation Columns, Chem. Eng. Commun., 2014.

GUERRA, R. G.; HERNÁNDEZ, J. G. S.; HERNÁNDEZ, S. Reducing Energy Consumption and CO2 Emissions in Extractive Distillation. Chem. Eng. Res. Des., v. 87, p. 145-152, 2008.

HERNÁNDEZ, S.; JIMÉNEZ, A. Design of Optimal Thermally-Coupled Distillation Systems Using a Dynamic Model. Chem. Eng. Res. Des., v. 74, p. 357-362, 1996.

KISS, A.; SUSZWALAK, D. Enhanced Bioethanol Dehydration by Extractive and Azeotropic Distillation in Dividing-Wall Columns . Sep. Purif. Technol., v 86, p. 70-78, 2012.

LI, G.; BAI P. New operation strategy for separation of ethanol-water by extractive distillation. Ind. Eng. Chem. Res., v.51, n.6, p.2723-2729, 2012.

MEIRELLES, A.; WEISS, S.; HERFURTH, H. Ethanol dehydration by extractive distillation. $J$. Chem. Technol. Biotechnol., v. 53, n. 2, p. 181-188, 1992.

OJEDA, M.;HERNÁNDEZ, J.; HERNÁNDEZ, S.; AGUIRRE, A.; KISS, A. Design and Optimization of an Ethanol Dehydration Process UsingStochastic Methods. Sep. and Purif. Technol., v. 105, p. 90-97, 2013.

SKOGESTAD, S.; DWIVEDI, D.; HALVORSEN, I. J., Control Structure Selection For Four-Product Petlyuk Column. Chem. Eng. Proc., v. 67, p. 49-59, 2013. 